\title{
Neurosensory disturbances after immediate loading of implants in the anterior mandible: an initial questionnaire approach followed by a psychophysical assessment
}

\author{
M. Abarca • D. van Steenberghe • C. Malevez • \\ J. De Ridder $\cdot$ R. Jacobs \\ Received: 12 December 2005 / Accepted: 20 June 2006 / Published online: 26 August 2006 \\ (C) Springer-Verlag 2006
}

\begin{abstract}
The aim of the study was to assess past and present neurosensory disturbances using a questionnaire and a psychophysical approach in patients treated with immediate loaded implants in the edentulous anterior mandible. A group of 65 patients (age range $30-84$ years, mean 58 years, 30 women) was enrolled. All were treated by means of three immediately loaded implants (Branemark Novum System ${ }^{\circledR}$ ). A self-administered questionnaire was used for data collection. The response rate was $89 \%$. Of the 58 responders, $33 \%(n=19)$ reported neurosensory disturbances after implant surgery. Nine of these patients (mean age 56 years, seven women) participated in an objective evaluation and were subjected to a psychological and several psychophysical tests. Psychological testing revealed no statistical differences between the patients, who had previously experienced subjective complaints, and the control group. Two-point discrimination and thermal sensation tests revealed no sensory lesions. The light touch sensation test at the lower lip indicated a more frequent reduction of tactility for the test group $(p \leq 0.03)$.
\end{abstract}

D. van Steenberghe is the holder of the P.I. Brånemark chair in osseointegration.

M. Abarca • D. van Steenberghe · J. De Ridder · R. Jacobs $(\square)$ Department of Periodontology, School of Dentistry,

Oral Pathology and Maxillo-Facial Surgery,

Faculty of Medicine, Catholic University of Leuven,

Kapucijnenvoer 7 ,

Leuven 3000, Belgium

e-mail: reinhilde.jacobs@med.kuleuven.be

C. Malevez

Department of Oral and Maxillo-Facial Surgery,

Faculty of Medicine, Free University of Brussels,

Route de Lennik 808,

Brussels 1010, Belgium
Neurosensory disturbances can occur in the anterior region of the mandible after implant surgery.

Keywords Oral implants $\cdot$ Symphysis .

Neurosensory disturbances $\cdot$ Mental nerve .

Psychophysical tests

\section{Introduction}

Nerve injury and specifically trigeminal nerve injury is known as a potential risk of many surgical procedures in the oral cavity in general $[17,23,30]$.

Usually after oral implant rehabilitation, the patient expects and experiences significant improvements, not only regarding jaw function, but also in relation to dental, facial, and even overall body image [22]. One can perfectly understand that the patient does not accept neural side effects, which might compromise his well-being.

Following the definitions of the Subcommittee on Taxonomy of the International Association for the Study of Pain 1986, the types of sensorial disturbances are principally anesthesia, paresthesia, or dysesthesia. These changes can be persistent according to the degree of damage of the nerve [31].

Sensory disturbances in the maxillofacial region could be associated with different surgical procedures, like placement of endosseous implants [3, 36, 37]. With regard to immediately loaded implants, the presence of postoperative sensory disturbances was not documented.

Brånemark et al. [5] developed a new approach for immediate loading using fixed prosthesis of prefabricated standard components in the edentulous mandible. This technique involves a flattening of the jaw crest, followed by 
the placement of the implants by means of prefabricated and thus not individualized surgical guides. Thus the distances (but not the depth of drilling) between the implants were always the same, considerably reducing the variation of the surgical procedure. Sometimes the distal implants were positioned near the mental foramen [5].

Damage to the mental nerve may result in loss of tactility and thus biting on the tongue or lip, drooling, painful sensations, and also interference with several jaw functions such as mastication, speech, hygiene maintenance, and social or psychosexual well-being [15].

Different methods were used to evaluate such sensory disturbances after the placement of dental implants. Ellies [11] in 1992 and Ellies and Hawker [12] in 1993 published two retrospectives studies based on the analysis of questionnaires.

Wismeijer et al. [36] applied in a prospective study a self-administrated questionnaire and the somatic questionnaire, the Hopkins Symptoms Checklist (HSCL). The latter is a questionnaire routinely used in psychology to estimate a patient's psychoneurological and/or psychosomatic discomfort. The somatic score of the HSCL was oriented on physical complaints and shows the level of a patient's perception of his/her physical state. The higher the somatic score (i.e., $25 \%$ in the study of Wismeijer et al. [36]), the more the patient tends to exaggerate physical complaints, but the risk of a sensory disturbance of the lower lip is a possible complication after implant surgery [38].

Bartling et al. [3] analyzed the neurosensory disturbances in a population of patients after oral implant placement, using a combination of psychophysical methods like soft brush, two-point discrimination, pain perception, and temperature sensitivity. A small number (8/94) of patients experience altered sensation after the placement of mandibular endosseous implants, but no permanent alteration was found.

Walton [37] published a prospective study of 75 subjects using one objective (the light touch sensation) test, associated with a subjective analysis (questionnaire); both methods were used before and after placement of two implants in the anterior mandible. In this study, $24 \%$ of subjects reported neurosensory disturbances in the short term after implant surgery in the anterior mandible, but the problem appears to be a transient one with only about $1 \%$ experiencing sensation changes 1 year after implant surgery [37].

After reviewing the related literature, it is clear that the proportion of patients with sensory disturbances varies among publications.

It is therefore essential to assess if neurosensory changes take place after the immediate loading of oral osseointegrated implants in the edentulous mandible in patients who received a fixed prosthetic construction on the day of implant insertion or the next day.
Distinguishing between dysesthesia, an unpleasant abnormal tactile sensation, and paresthesia, an abnormal (not painful) and often decreased sensation, is the first step in defining the character of the neurosensory disturbance reported by a patient. Further differentiation between paresthesia and hypoesthesia, which is a reduction in the level of sensation, and finally anesthesia, the complete absence of any sensation, is important from all viewpoints. In the presence of dysesthesia, the differentiation must be established between spontaneous and a stimulus-induced unpleasant sensation. The clinical approach and sometimes legal implications of these different conditions are evident [6].

Besides clinical evaluation, it must be understood that evaluation of nerve injuries such as demyelinization due to compression (neuropraxia), distal Wallerian degeneration with intact cell tubes (axonotmesis), or proximal and distal Wallerian degeneration with disparate Schwann cell tubes (neurotmesis) is an impossible mission for the clinician. Nevertheless, if no spontaneous return of tactile sensibility is noted within 3-6 months, the permanent loss of continuity of some or all the elements of the nerve trunk should be expected $[11,27]$. Some observations indicate that the return to normal tactile sensibility may even occur after 2 to 3 years [12]. The differences between laboratory and clinical results are obvious.

In some studies, questionnaires were used to evaluate the presence of sensory disturbances. Such methodology is clinically helpful and is a good basis for more detailed and objective evaluations.

Immediate loading of oral implants was proposed as an alternative protocol in the rehabilitation of partially or fully edentulous patients [8]. Surprisingly enough, no study has yet referred to the possible different neural sensibility when loading is imposed immediately after or together with the placement of the implants. This tactile sense aspect is relevant especially if we consider that the prosthetic rehabilitation (implying by example a full occlusal contact) is functional within one or a few hours after the implant placement. Thus, the patient's awareness of the load imposed on the implants can be a key issue to avoid undue load transfer on the implant-bone interface.

The overall aim of the present research is to objectively evaluate the neurosensory disturbances and/or function occurring after placement of oral implants in the anterior region of the mandible.

\section{Materials and methods}

This study comprised a total of 65 patients (age range 3084 years, mean age 58 years; 30 women). All patients were treated by means of immediately loaded implants in the 
anterior mandible with the Brånemark Novum ${ }^{\circledR}$ system approach. Surgery took place at the Department of Periodontology, Catholic University Leuven (55 patients, 3 surgeons), and at the Department of Oral and Maxillofacial Surgery, Erasmus Hospital, Free University of Brussels (10 patients, 2 surgeons).

Selection criteria included (1) placement of implants in the anterior mandible using Brånemark Novum System ${ }^{\mathbb{R}}$ (NobelBiocare AB, Gothenburg, Sweden); and (2) no history of neurological disorder.

An ad hoc multiple choice questionnaire (13 questions) was designed to record past and present neurosensory disturbances in these patients. The clinical history of the patient was used, and according to the selection criteria, a self-administered questionnaire was sent out to the 65 patients. The questionnaire was sent by mail to the patients with the request to complete it and return it to the clinic. The questionnaire was designed by experienced periodontologists, prosthodontists, and one psychologist (see Appendix for the questionnaire). The answers to the questions were analyzed and data were collected by this same team.

An objective evaluation took place after analysis of the questionnaire. During this evaluation psychological and psychophysical tests took place. The clinical evaluation of trigeminal nerve injuries suggested by Zuniga and Essick [39] in 1992 was used as basis in the test and control population.

A psychological test: the SCL-90-R ${ }^{\circledR}$ (Symptom Checklist-90-Revised) was applied. The SCL-90- ${ }^{\circledR}$ measures the psychoneurotic-somatic nonwellness (Psychoneuroticism) of patients [10]. The SCL-90- $\mathrm{R}^{\circledR}$ is different from the HSCL because it considers a broader area of psychopathology. The scale of psychoneuroticism in patients is assessed. It reveals the global level of recent psychological and also physical dysfunction. In the present study, the intensity of somatic complaints was considered important. The SCL-90- $\mathrm{R}^{\circledR}$ scale reveals complaints, loaded with a general feeling of physical dysfunction, as a result from functional problems.

After completion of the questionnaire, each patient was interviewed using a standardized series of "key questions" on altered feeling in the chin, lips, tongue, and cheek. Each time a distinction was made between the right and left sides of the face. Typical questions were as follows:

- How would you describe the altered feeling?

- Do you notice the altered feeling constantly or only when touching the area, or chewing, or talking?

- Is it painful? Where? Transient or constant?

- Does it start spontaneously or is it evoked by touching, chewing, or speaking?

- What exacerbates the pain?

- What relieves the pain?

After thorough questioning about the patient's general and oral medical history, an extra- and intraoral clinical examination took place, including palpation and/or percussion, to detect eventual provoked pain at the site of injury. Finally, inspection of the oral cavity was performed to find eventual evidence of nerve injury, self-induced trauma, etc.

In the present study three psychophysical tests were selected: two-point perception at the lower lip, both left and right side (Fig. 1); thermal sensitivity at the lower lip and gingiva of the anterior lower jaw, both left and right side (Fig. 2); and light touch sensation at the lower lip and gingiva of lower jaw, both left and right side (Fig. 3).

Psychophysical tests demand a thorough consciousness and active participation of the patients and a quiet environment [20]. A combination of both psychophysical tests with testing tools adapted to the intraoral and perioral sites were used. The light touch sensation on the other hand was tested using the original Semmes-Weinstein Aesthesiometer $^{\circledR}$ (Stoeling Company, Wood Dale, USA) device. To determine the threshold level the staircase method was applied. In the light touch sensation and static two-point discrimination, eight maximum and eight minimum values were recorded. Finally, in the thermal sensitivity test, all subjects were tested with ten trials. For a more detailed methodology of the procedures for sensory testing, see Jacobs et al. [21].

The collected data were statistically analyzed using the Statistica for Windows $5.1^{\circledR}$ (Stat Soft, Tulsa, OK, USA).

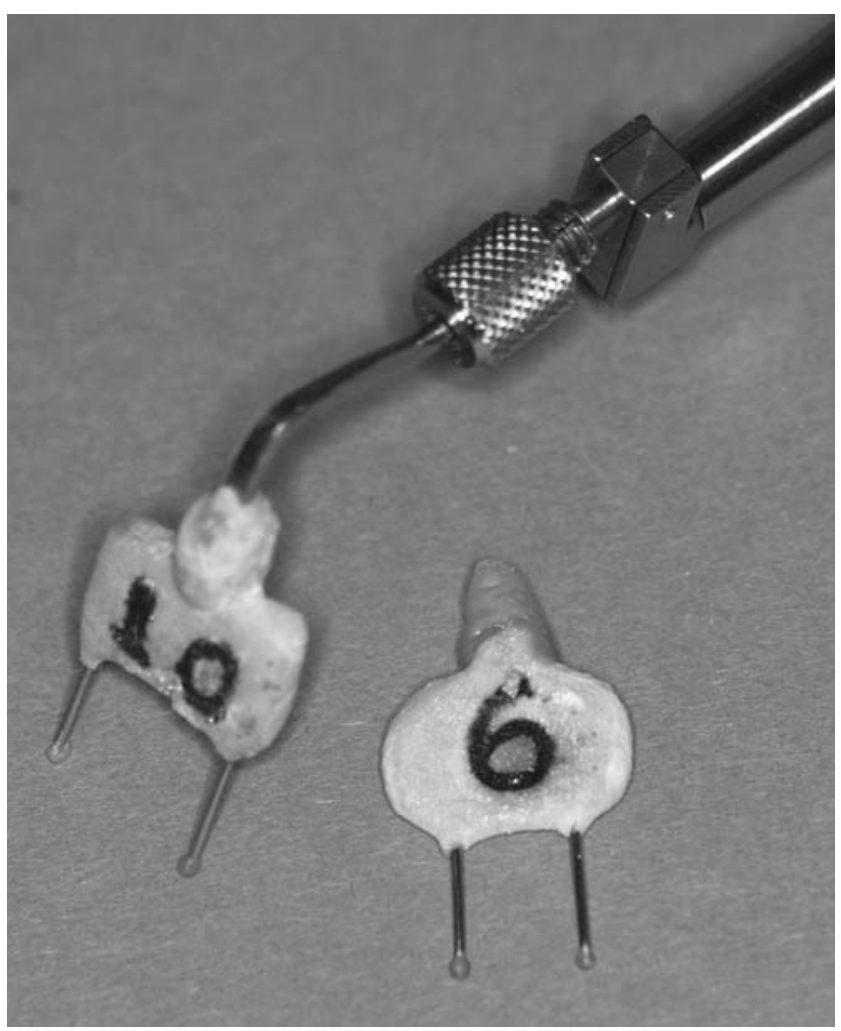

Fig. 1 Two-point discrimination instrument 


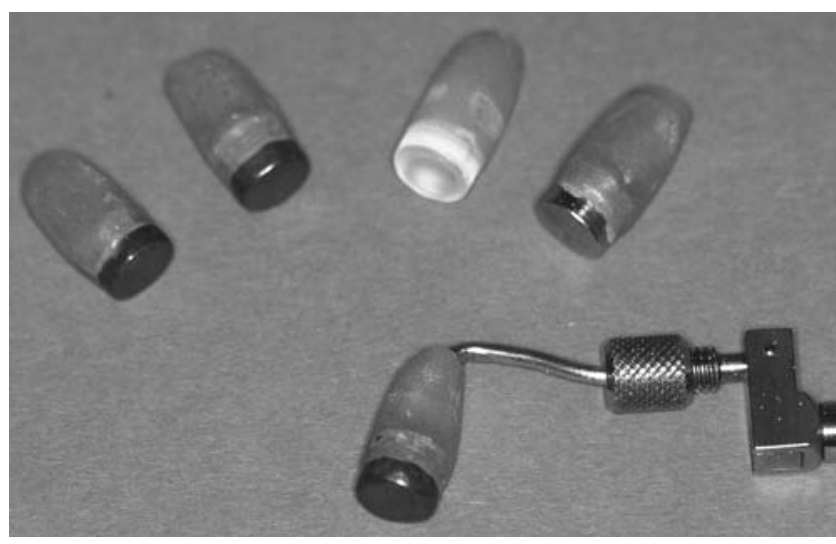

Fig. 2 Thermal sensitivity instrument

A Mann-Whitney U test was applied to the threshold levels in the test and the control groups.

\section{Results}

Fifty-eight of the 65 patients (89\%) completed the questionnaire and returned it to the hospital. Systemic diseases like cardiac, respiratory, endocrine, and renal diseases, allergic reactions, and psychological (depression) problems were detected in $46 \%(n=30)$ of the patients.

The mean time between the placement of the implants and the reception of the questionnaire was 20 months (range 8-40 months).

The analysis of the questionnaire showed that 33\% $(n=19)$ of patients reported a kind of neurosensory disturbance after the placement of the implants (range 8-24 months). The age range of this subpopulation was

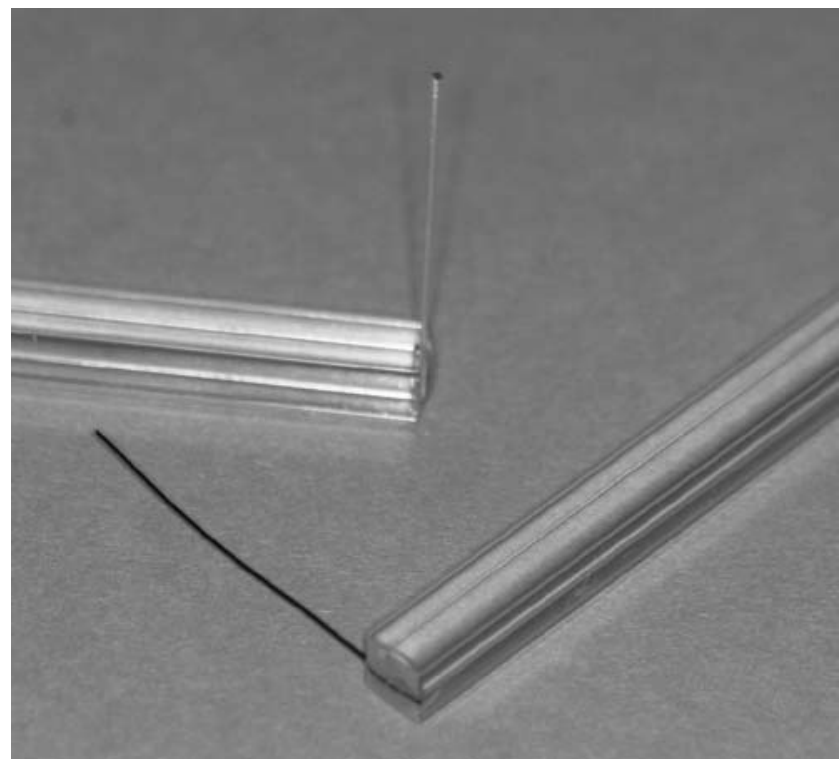

Fig. 3 Light touch sensation (Semmes-Weinstein Aesthesiometer ${ }^{\circledR}$ ) instrument between 30 and 71 years (mean age 56, 13 women). This data are not different from the remaining group.

The duration of this postsurgical neurosensory disturbance after the implant surgery was less than 3 months in $58 \%(n=11)$ of the patients. However, eight patients were still suffering from a disturbance. For them the problem persisted for a period between 8 and 21 months.

The most commonly affected sites in the 19 patients were the gingiva only (6 patients), the inferior lip only (4 patients), and the chin (4 patients). One of the patients did not remember or could not determine the affected zone.

Speaking and drinking (five patients) were the oral activities most commonly impaired by the altered sensations. An important part of the affected population group (12 patients) didn't complain about problems with oral function or daily activity.

The most common reported sensation was numbness (nine patients), followed by cutting, beating, and itching reported by two patients.

Only one patient considered that the benefits of a fixed prosthesis did not outweigh the disadvantages that she had experienced as a result of disturbances in sensation of the lower jaw. She considered that she would not have done this surgery again, if she had been informed beforehand about the potential sensory changes in the orofacial region.

From the 19 patients, 9 volunteered to participate in the objective evaluation (test group). The test group was 3071 years old (mean age 56 years, seven women).

A control group of volunteers $(N=9)$ was also enrolled. Their age ranged from 49 to 71 years (mean age 63 years, all women). The mean observation time in this group since the surgery (two implants placed in the anterior mandible after a two-stage protocol) was 18 months (range 11-22 months).

As psychological test, the SCL-90- ${ }^{\circledR}$ test was applied for symptom measurement of patient treatment outcomes and their degree of somatization of the symptoms. The psychophysical tests included three neurosensory evaluations: two-point discrimination, thermal sensitivity, and light touch sensation. The staircase method of limits was applied to determine the tactile threshold. An age- and gender-matched group of patients who had undergone similar surgery (two implants in the symphyseal region) in the same area, but without reporting sensory disturbances, served as control.

\section{Results of the psychological and psychophysical tests}

As mentioned above, each of the 19 patients of the selfdeclared affected population was invited for a clinical evaluation and 9 of the 19 patients accepted to participate. The time span between surgery and psychophysical 
evaluation was on average 29 months (range 1949 months). During the clinical interview, before the actual objective testing took place, none of the nine patients had remaining complaints or clinical symptoms such as drooling or tongue bite wounds that could indicate a sensory disturbance.

However, at the reception of the questionnaire, which had to be mailed after the examination session, five of the nine patients with self-declared neurosensory disturbances still reported having them. In the remaining four patients the subjective neurosensory disturbances were completely resolved.

No major complaints were recorded after the evaluation of the SCL-90- $\mathrm{R}^{\circledR}$. The scores of the SCL-90- $\mathrm{R}^{\circledR}$ of the test $(N=9)$ and control group $(N=10)$ revealed no statistic differences, neither on the global scale of neuroticism, nor on the dimension of somatic complaints. This means that the level of complaints of both groups was similar.

After clinical examination and considering the negative interview for unpleasant dysesthesia and pain, it was concluded that only potential signs of paresthesia were currently present in the affected patients. Two-point discrimination, thermal sensation, and light touch sensation at the gingival level show no significant difference between test and control groups (Table 1) [14, 16, 26, 28].

The light touch sensation of the lower lip was significantly impaired in the test group (Mann-Whitney U test). There was a statistical difference for both sides $(p \leq 0.03)$ between test and control groups.

Systemic diseases have a significant effect on the outcome of the light touch testing at the lower lip. The light touch sensation of the lower lip revealed a statistical difference $(p \leq 0.04)$ for both sides.

\section{Discussion}

The anterior region of the mandible was always considered as a "safe zone" for the use of oral implants. This is particularly true concerning the high success rate of oral osseointegrated implants [25]. Nevertheless, there is an important difference between the reported implant success rate with specific surgical technique and the postsurgical changes to function, sensory mechanisms, and the physiological integration in the human body. Anatomical considerations in the anterior region of the mandible and the skills and experience of the surgeon are also important [24].

It is surprising to note that the present methodology allowed us to observe a very high percentage of subjective postoperative complaints. These results are in agreement with others, i.e., Ellies [11] with $37 \%$ and Ellies and Hawker [12] with $36 \%$. This high degree of concordance for the percentages of incidence is interesting, considering the different surgical techniques used and cultural and sometimes ethnic differences between the three involved populations (Canada, Australia, and Belgium).

It was not possible, based on the subjective data, to establish any correlation between the systemic diseases presented in the study population and the reported sensory disturbances (i.e., impairment of perception in a patient with diabetes) $[2,4]$.

It is interesting to know that eight patients had the impression to be affected by some kind of persistent neurosensory disturbance, most probably paresthesia or hypoesthesia, more than 12 months after the surgery. Nevertheless, besides these results, a majority of these affected patients considered that the benefits outweigh this kind of transient or permanent disadvantages, and consider

Table 1 Overview of psychophysical tests scores between test group, control group, and reference values

\begin{tabular}{|c|c|c|c|c|}
\hline Type test/Region & Test group & Control group & Reference values & Reference number \\
\hline $\mathrm{T}^{\circ} \mathrm{S} / \mathrm{LLLS}$ & $0.8(\mathrm{CR})$ & $0.9(\mathrm{CR})$ & $0.8(\mathrm{CR})$ & 18 \\
\hline $\mathrm{T}^{\circ} \mathrm{S} / \mathrm{LLRS}$ & $0.9(\mathrm{CR})$ & $0.9(\mathrm{CR})$ & $0.8(\mathrm{CR})$ & 18 \\
\hline $\mathrm{T}^{\circ} \mathrm{S} / \mathrm{LGLS}$ & $0.8(\mathrm{CR})$ & $0.8(\mathrm{CR})$ & $0.8(\mathrm{CR})$ & 18 \\
\hline $\mathrm{T}^{\circ} \mathrm{S} / \mathrm{LGRS}$ & $0.8(\mathrm{CR})$ & $0.8(\mathrm{CR})$ & 0.8 (CR) & 18 \\
\hline \multirow[t]{3}{*}{ 2PD/LLLS } & $3.4 \mathrm{~mm}$ & $4.5 \mathrm{~mm}$ & $6.1 \pm 3.1 \mathrm{~mm}$ & 19 \\
\hline & & & $3.3 \pm 1.6 \mathrm{~mm}$ & 20 \\
\hline & & & $2 \pm 4 \mathrm{~mm}$ & 21,22 \\
\hline \multirow[t]{3}{*}{ 2PD/LLRS } & $3.4 \mathrm{~mm}$ & $4.8 \mathrm{~mm}$ & $6.1 \pm 3.1 \mathrm{~mm}$ & 19 \\
\hline & & & $3.3 \pm 1.6 \mathrm{~mm}$ & 20 \\
\hline & & & $2 \pm 4 \mathrm{~mm}$ & 21,22 \\
\hline LTS/LGLS & $7 \mathrm{NF}^{\mathrm{a}}$ & $6 \mathrm{NF}^{\mathrm{a}}$ & $4(2.83) \mathrm{NF}$ & 19 \\
\hline LTS/LGRS & $7 \mathrm{NF}^{\mathrm{a}}$ & $7 \mathrm{NF}^{\mathrm{a}}$ & $4(2.83) \mathrm{NF}$ & 19 \\
\hline
\end{tabular}

$T^{\circ} S$ Thermal sensation, $L L L S$ lower lip left side, $L L R S$ lower lip right side, $L G R S$ lower gingiva right side, $L G L S$ lower gingiva left side, $C R$ correct ratio, $2 P D$ two-point discrimination, $\mathrm{mm}$ millimeters, $L T S$ light touch sensation, and $N F$ the number of the filament

${ }^{a}$ Mean value of von Frey hair 
that they would accepted an implant surgery again even if they knew about the present complication.

Normal somatic sensation reflects a continuous day and night monitoring process. Little of this activity reaches consciousness under ordinary conditions. Disordered sensation is alarming and dominates the sufferer's attention. As expected from the neuroanatomical knowledge recently collected, neurosensory disturbances regularly occur in the anterior region of the mandible after surgery. Anatomical factors like the presence of an anterior loop, handling of the mental nerve during surgery, or the perforation of the incisive nerve canal can all provoke such disturbances.

As mentioned above, the Brånemark Novum ${ }^{\circledR}$ technique involves a flattening of the jawbone. This procedure can be considered rather invasive and can damage, in severely resorbed jaws, the incisive canal or the mental nerve emerging at the crestal level. The relationship between a reduction of the crestal jawbone and neurosensory disturbances could not be traced in the literature. However, bone chin grafting procedures present some similarities. von Arx et al. [35] recently reported $8.1 \%$ of neurosensory disturbances after 6 months in patients who underwent such procedures.

For some systemic conditions, it was reported that persons can be more prone to sensory disturbances. Peripheral neuropathy in people with scleroderma is thought to be rare, however, nerve conduction studies showed abnormalities in patients with a mean disease duration of 10 years or longer [29]. Polyneuropathies in mild or severe diabetic patients often cause subclinical damage of the trigeminal nerve. Moreover, their sensory complaints in the perioral area often remain unnoticed and the dysfunction undiagnosed [9]. Age by itself also has an influence, especially when repair is concerned. The younger the subject, the greater the degenerative response but the quicker and more complete the overall recovery [7].

Tactile threshold assessment reveals that detection of monofilaments up to $0.023 \mathrm{~g}$ (monofilament number 2) can be considered normal in the orofacial region $[14,37]$.

Neurophysiological recordings of the masseter reflex, the mental nerve blink reflex, or evoked potentials are all useful in evaluating trigeminal nerve damage. This was specifically shown for damage of the inferior alveolar nerve $[19,32,33]$. However, evaluation of nerve damage in the symphyseal region was not reported in the literature. The number of nerves innervating this region, the vicinity of interfering structures (e.g., tongue, saliva, and labial muscles), and anatomical variations make this a difficult but challenging task.

In humans, several reports show that during the stimulation of peripheral sensory limb nerve examined after surgical repair (time span between 5 and 20 years), the sensory function remained deficient and often included abnormal sensory disorders [1]. It must also be considered that the loss of tactile sensitivity after surgery is not always reflected in abnormal psychophysical test results [13]. Furthermore, it is also possible, as shown by the collected data in this study, that an abnormal test result, particularly the light touch sensation test, does not reflect clinical reality. In other words, the patient does not always detect the loss of sensitivity.

It should be stressed that the selection of a control group of patients treated by means of two implants in the symphyseal region was principally motivated by the intent to have an age- and gender-matched group. The selection of a control group among patients treated with the Novum ${ }^{\circledR}$ system but without neurosensory complaints would not have allowed this.

It must also be considered that sometimes thresholds of the psychophysical test are not easy to reach in the oral cavity; the devices were not originally designed for this region, particularly light touch sensation [33].

Not less important is the fact that $95 \%(n=17)$ of the affected population considers that the treatment benefits outweigh the transient disadvantages, and that $18 / 19$ of the patients consider that they would follow an implant surgery again if they knew beforehand the changes in sensation after the surgery.

There are no data in literature to compare neurosensory disturbances after immediate loading with those after the two-stage protocol. It is clear that it is difficult for the patient to distinguish between postoperative inconveniences, early functional adaptation, and real neurosensory dysfunction. Only a differential objective diagnosis can do so.

A meticulous preoperative planning of the surgery, even in an improperly so-called safe region of the jaws, like the symphyseal region, might avoid many neural disturbances [18].

In this perspective, the use of cross-sectional images and the transfer of the planning to the operative field may be considered [34].

\section{Conclusions}

The use of a questionnaire to determine the presence or absence of a problem after a medical procedure is easy and inexpensive; but to clarify the type, magnitude, extension, and eventual persistence of the neurosensory disturbance, the use of objective methods (i.e., psychophysical methods) in the evaluation of a population affected by any sensory disturbance, when complaints are detected, is highly recommended. 
The objective follow-up revealed that patients are often not impaired by, and even not aware of, neurosensory dysfunctions after implant surgery in the anterior mandible. Objective tests indicate however that tactile threshold levels may be elevated after such surgery. None of the patients suffering from this impaired tactile function seems to have functional deficits resulting from it.

Based on these data, proper preoperative planning using cross-sectional imaging can be advised even for surgical procedures in the symphyseal region.

\section{Appendix}

Questionnaire

\section{Dear patient,}

In the next pages you can find several questions about your implant surgery in the lower jaw.

The objective of these questions is to evaluate if you have or had an alteration of sensibility after the placement of the implants in the lower jaw.

Put an $x$ before the correct answer.

Please try to complete this questionnaire to the very best.

1) After your implant surgery, did you experience a change in feeling or sensation of your lower lip, chin or gums?

_ Yes _ _No If yes, please indicate _ lower lip _ chin _ gums

\section{Dear Patient,}

If your answer was "No", it isn't necessary to follow with the questionnaire. However for our service, your answer is very important for our database.

Please send us the questionnaire by mail in the prepared envelope.

Thank you very much for your cooperation.

If your answer for the question number 1 was "Yes" please continue with the questionnaire.

2) If you have experienced a changed sensation in an area of the lower jaw was it temporary (one day to several months) or is it still present? - Temporary Persistent

3) If the change was temporary, how long did it last?

$$
\begin{aligned}
& <\text { (less) _ 6-12 months } \\
& 1 \text { week } \\
& \text { _ 1-4 weeks _ _ }>\text { (more) } 1 \text { year, please state how long } \\
& \text { 1-3 months } \\
& \text { 3-6 months }
\end{aligned}
$$

4) Did the change in sensation of your lower jaw affect your ability to continue your daily routine?

-Yes _ N No

5) Did the changed sensation affect your ability to perform any of the following activities?

$\begin{array}{ll}\text { _Speaking } & \text { Tasting } \\ \text { Eating } & \text { - Whistling } \\ \text { _Drinking } & \text { - Kissing } \\ \text { - Swallowing } & \text { _ Other, please specify }\end{array}$

\begin{tabular}{|c|c|}
\hline Burning & _Tickling \\
\hline Hot & Itching \\
\hline Prickling & Numb \\
\hline Penetrating & Frozen \\
\hline Cutting & Prurience \\
\hline Tearer & Electric \\
\hline Ardent & Palpitatic \\
\hline
\end{tabular}

6) Which side of your lower jaw is (was) affected?

$\begin{array}{ll}\text { Right } & \text { Both right and left sides } \\ \text { _Left } & \text { I I don't remember which side }\end{array}$

7) Which of the following words best describes the change in sensation you have experienced (please select only one word!)?

\section{Dear patient,}

If you have selected one word of the left column please continue with this questionnaire.

If you have selected one word of the right column go to the question 12.

Describing a pain or feeling is often difficult. Try to describe your pain as accurately as possible.

In the next question you have a word on the left side and a word on the right side.

Between the words you have a line. On the line you put a little $x$ [eks] $(x)$ in the zone most representative, in other words take the next question like a "thermometer" to measure the intensity of pain.

8) The type of pain is (or was):

Insupportable Supportable

9) Is this region disturbing during the night?

Yes

No

10) Do you occasionally take painkillers (i.e. aspirins, paracetamol) to control this pain? Attention: The analgesics you took immediately after the placement of the implants must not be considered.

_Yes__ No If so, which painkillers do you take?

If your answer to question 10 was "No" don't fill in the question 11. 


\section{1) Do these painkillers relieve your pain?}

-Yes _ N No

12) Did you feel that the benefits to your implant surgery outweigh the disadvantages you have experienced as a result of changes in sensation of your lower jaw?

-Yes _ No

13) Would you go through implant surgery again if you knew you would have the changes in sensation that you have experienced?

- Yes _ N No

\section{Dear patient, \\ You have finished the questionnaire; now please return the questionnaire by mail in the envelope that we have prepared for you. \\ Thank you very much for your cooperation.}

\section{References}

1. Almquist E, Eeg-Olofsson O (1970) Sensory-nerve-conduction velocity and two-point discrimination in sutured nerves. J Bone Joint Surg Am 52:791-796

2. Arzouman MJ, Otis L, Kipnis V, Levine D (1993) Observations of the anterior loop of the inferior alveolar canal. Int $\mathrm{J}$ Oral Maxillofac Implants 8:295-300

3. Bartling R, Freeman K, Kraut RA (1999) The incidence of altered sensation of the mental nerve after mandibular implant placement. J Oral Maxillofac Surg 57:1408-1410

4. Bertelsmann FW, Heimans JJ, van Rooy JC, Heine RJ, van der Veen EA (1986) Reproducibility of vibratory perception thresholds in patients with diabetic neuropathy. Diabetes Res 3:463-466

5. Brånemark PI, Engstrand $\mathrm{P}$, Ohrnell LO, Grondahl K, Nilsson $\mathrm{P}$, Hagberg K, Darle C, Lekholm U (1999) Brånemark Novum: a new treatment concept for rehabilitation of the edentulous mandible. Preliminary results from a prospective clinical followup study. Clin Implant Dent Relat Res 1:2-16

6. Buchthal F, Kuhl V (1979) Nerve conduction, tactile sensibility, and the electromyogram after suture or compression of peripheral nerve: a longitudinal study in man. J Neurol Neurosurg Psychiatry 42:436-451

7. Calhoun KH, Gibson B, Hartley L, Minton J, Hokanson JA (1992) Age-related changes in oral sensation. Laryngoscope 102:109-116

8. Cochran DL, Morton D, Weber HP (2004) Consensus statements and recommended clinical procedures regarding loading protocols for endosseous dental implants. Int J Oral Maxillofac Implants 19:109-113

9. Cruccu G, Agostino R, Inghilleri M, Innocenti P, Romaniello A, Manfredi M (1998) Mandibular nerve involvement in diabetic polyneuropathy and chronic inflammatory demyelinating polyneuropathy. Muscle Nerve 21:1673-1679

10. Derogatis LR, Lipman RS, Rikkels K, Uhlenhuth EH, Covi L (1974) The Hopkins Symptoms Checklist. A self report symptom inventory. Behav Sci 19:1-15

11. Ellies LG (1992) Altered sensation following mandibular implant surgery: a retrospective study. J Prosthet Dent 68:664-671
12. Ellies LG, Hawker PB (1993) The prevalence of altered sensation associated with implant surgery. Int J Oral Maxillofac Implants 8:674-679

13. Essick GK, Patel S, Trulsson M (2002) Mechanosensory and thermosensory changes across the border of impaired sensitivity to pinprick after mandibular nerve injury. J Oral Maxillofac Surg 60:1250-1266

14. Fogel ML, Stranc MF (1984) Lip function: a study of normal lip parameters. Br J Plast Surg 37:542-549

15. Greeg JM (1992) Abnormal responses to trigeminal nerve injury. Clinical syndromes, surgical pathology, and neural mechanisms. Oral Maxillofac Surg Clin North Am 4:339-351

16. Grushka M, Sessle BJ, Howley TP (1987) Psychophysical assessment of tactile, pain and thermal sensory functions in burning mouth syndrome. Pain 28:169-184

17. Hallin RG, Wiesenfeld Z, Lindblom U (1981) Neurophysiological studies on patients with sutured median nerves: faulty sensory localization after nerve regeneration and its physiological correlates. Exp Neurol 73:90-106

18. Harris D, Buser D, Dula K, Gröndahl K, Haris D, Jacobs R, Lekholm U, Nakielny R, van Steenberghe D, van der Stelt $P$ (2002) European Association for Osseointegration. E. A. O. guidelines for the use of diagnostic imaging in implant dentistry. A consensus workshop organized by the European Association for Osseointegration in Trinity College Dublin. Clin Oral Implants Res 13:566-570

19. Jaaskelainen SK (2004) The utility of clinical neurophysiological and quantitative sensory testing for trigeminal neuropathy. J Orofac Pain 18:355-359

20. Jacobs R, Wu CH, Goossens K, Van Loven K, Van Hees J, Van Steenberghe D (2002) Oral mucosal versus cutaneous sensory testing: a review of the literature. J Oral Rehabil 29:923-950

21. Jacobs R, Wu CH, Van Loven K, Desnyder M, Kolenaar B, van Steenberghe D (2002) Methodology of oral sensory tests. J Oral Rehabil 29:720-730

22. Kiyak HA, Beach BH, Worthington P, Taylor T, Bolender C, Evans J (1990) Psychological impact of osseointegrated dental implants. Int J Oral Maxillofac Implants 5:61-69

23. LaBanc JP (1992) Classification of nerve injuries. Oral Maxillofac Surg Clin North Am 4:285-296

24. Mraiwa N, Jacobs R, Moerman P, Lambrichts I, van Steenberghe D, Quirynen M (2003) Presence and course of the incisive canal in the human mandibular interforaminal region: two-dimensional imaging versus anatomical observations. Surg Radiol Anat 25:416-423

25. Naert I, Gizani S, Vuylsteke M, van Steenberghe D (1999) A 5 -year prospective randomized clinical trial on the influence of splinted and unsplinted oral implants retaining a mandibular overdenture: prosthetic aspects and patient satisfaction. J Oral Rehabil 26:195-202

26. Posnick JC, Zimbler AG, Grossman JA (1990) Normal cutaneous sensibility of the face. Plast Reconstr Surg 86:429-433

27. Robinson PP (1988) Observations on the recovery of sensation following inferior alveolar nerve injuries. Br J Oral Maxillofac Surg 26:177-189

28. Robinson PP, Loescher AR, Smith KG (2000) A prospective, quantitative study on the clinical outcome of lingual nerve repair. Br J Oral Maxillofac Surg 38:255-263

29. Schady W, Sheard A, Hassell A, Holt L, Jayson MI, Klimiuk P (1991) Peripheral nerve dysfunction in scleroderma. Q J Med 80:661

30. Schultze-Mosgau S, Erbe M, Rudolph D, Ott R, Neukam FW (1999) Prospective study on post-traumatic and postoperative sensory disturbances of the inferior alveolar nerve and infraorbital nerve in mandibular and midfacial fractures. J Craniomaxillofac Surg 27:86-93 
31. Subcommittee on Taxonomy International Association for the Study of Pain (1986) Classification of chronic pain. Description of chronic pain syndromes and definition of pain terms. Pain Suppl 3:S1-226

32. Teerijoki-Oksa T, Jaaskelainen S, Forssell K, Virtanen A, Forssell $\mathrm{H}$ (2003) An evaluation of clinical and electrophysiologic tests in nerve injury diagnosis after mandibular sagittal split osteotomy. Int J Oral Maxillofac Surg 32:15-23

33. Trulsson M, Essick GK (2004) Mechanosensation. In: Miles TS, Nauntofte B, Svensson P (eds) Clinical oral physiology. Quintessence Publishing, Copenhagen, Denmark, p 167

34. van Steenberghe D, Naert I, Andersson M, Brajnovic I, Van Cleynenbreugel J, Suetens P (2002) A custom template and definitive prosthesis allowing immediate implant loading in the maxilla: a clinical report. Int $\mathrm{J}$ Oral Maxillofac Implants $17: 663-670$
35. von Arx T, Hafliger J, Chappuis V (2005) Neurosensory disturbances following bone harvesting in the symphysis: a prospective clinical study. Clin Oral Implants Res 16:432-439

36. Wismeijer D, van Mass M, Vermeeren J, Kalk W (1997) Patient's perception of sensory disturbances of the mental nerve before and after implant surgery: a prospective study of 110 patients. Br J Oral Maxillofac Surg 35:254-259

37. Walton JN (2000) Altered sensation associated with implants in the anterior mandible: a prospective study. J Prosthet Dent $83: 443-449$

38. Zuniga JR (1992) Normal responses to nerve injury: histology and psychophysics of degeneration and regeneration. Oral Maxillofac Surg Clin North Am 4:323-337

39. Zuniga JR, Essick GK (1992) Contemporary approach to the clinical evaluation of trigeminal injuries. Oral Maxillofac Surg Clin North Am 4:353-367 